\title{
A comunicação da equipe de enfermagem com o paciente em cuidados paliativos
}

\section{The communication of the nursing team with patients in palliative care}

\author{
Everton Fernando Alves ${ }^{1}$
}

\begin{abstract}
Resumo
A proposta deste estudo é a de refletir sobre a comunicação em cuidados paliativos e evidenciar estratégias utilizadas na comunicação efetiva entre a equipe de enfermagem, o paciente terminal e a família. A estratégia metodológica que o conduziu está fundamentada na reflexão contextualizada do tema. Neste sentido desvela-se que, para a equipe de enfermagem, a assistência ao doente terminal é uma tarefa difícil, que suscita sensação de tristeza, frustração, impotência e até mesmo culpa por reais ou supostas falhas na assistência prestada. Deste modo, muitos profissionais utilizam a negação, a fuga e a aparente frieza como mecanismos de defesa no enfrentamento da situação. Ao longo dessa reflexão são expostos alguns aspectos que possibilitam desenvolver habilidades na comunicação empática, percebida como tarefa que requer da equipe de enfermagem uma mudança de foco e atitude. Além da escuta cuidadosa, a veracidade, o bom humor e o toque terapêutico, que constituem estratégias para uma comunicação efetiva na terminalidade da vida.
\end{abstract}

Palavras-chave: Comunicação. Cuidados paliativos. Doente terminal. Família.

\begin{abstract}
The article consists of a contextualized reflection on the communication in palliative care with the purpose of explaining strategies used for effective communication among the nursing, terminally ill and his family. In that sense, it was observed that for the nurse to assist the terminally ill is a difficult task, which raises sensation of sadness, frustration, impotence and even failure in the rendered attendance. This way, many professionals use denial, escaping, and the apparent coldness as defense mechanisms to cope with situation. Throughout this discussion are exposed some aspects that enable developing empathic communication skills, perceived as a task that requires nursing staff a shift in focus and attitude. Apart from careful listening, truthfulness, good humor and therapeutic touch, forming strategies for effective communication in the terminally ill life.
\end{abstract}

Keywords: Communication. Hospice care. Terminally ill. Family.

${ }^{1}$ Enfermeiro. Especialista em Saúde do Trabalhador pela Universidade Estadual do Norte do Paraná - UENP. Mestrando do Programa de Pós-graduação em Ciências da Saúde pela Universidade Estadual de Maringá - UEM. Rua rio Paranapanema, 779, Branca Vieira, CEP: 87043-150, Maringá, Paraná. E-mail: evertonando@hotmail.com. 


\section{Introdução}

Atualmente, existe um número maior de pacientes morrendo, não apenas por câncer, mas também pelo envelhecimento da população que traz consigo muitas doenças crônicodegenerativas, aumentando o percentual de doente em estado terminal nos hospitais ou em seus domicílios (RONCARATI et al., 2003; SILVA; HORTALE, 2006).

A terminalidade de vida é conceituada quando todos os recursos terapêuticos curativos se encontram esgotados e quando já não há mais tempo nem a oportunidade de se fazer algo. O indivíduo se torna irrecuperável e caminha para a morte, sem que se consiga reverter este caminhar (RONCARATI et al., 2003; SILVA; HORTALE, 2006).

A fase da terminalidade humana torna o processo do cuidar mais complexo, já que o paciente precisa ser cuidado além do processo degenerativo da própria idade e doenças associadas. O cuidado ao paciente terminal precisa ser ofertado de forma holística, ou seja, reconhecendo o indivíduo que está em fase terminal como um ser completo que necessita de assistência em sua esfera biopsicossocioespiritual (OLIVEIRA; SILVA, 2010; PINTO et al., 2011).

Neste contexto torna-se fundamental o acompanhamento constante da equipe de enfermagem em todas as etapas do tratamento ao paciente sem possibilidades de cura, como também à família. Entretanto, é visto atualmente, que suposições errôneas a respeito do pensamento de que não há mais nada a se fazer pelo paciente tem sido alvo de questionamentos, pois enquanto há vida existe a necessidade do cuidado da equipe de enfermagem. A atuação dos profissionais da enfermagem é primordial e indispensável para promover o máximo de conforto ao paciente em sua terminalidade humana, a fim de que ele e sua família possam vivenciar o processo de morte com dignidade e ambos utilizem da melhor forma possível o tempo que lhes resta. Isto significa auxiliá-los na busca da qualidade de vida, mesmo quando não é mais possível adicionar quantidade
(ARAÚJO; SILVA, 2003; SANTANA et al., 2009).

O conceito de cuidados paliativos evoluiu ao longo do tempo à medida que esta filosofia de cuidado foi se desenvolvendo em muitas regiões do mundo. Segundo a Organização Mundial da Saúde, o termo cuidados paliativos significa os cuidados ativos e totais do paciente cuja doença não responde mais ao tratamento curativo. Tratase de uma abordagem de cuidado diferenciada, que visa melhorar a qualidade de vida do paciente e seus familiares, por meio da adequada avaliação e tratamento para alívio da dor e sintomas, além de proporcionar suporte psicossocial e espiritual (WORLD HEALTH ORGANIZATION, 2010).

$\mathrm{Na}$ assistência de enfermagem, a comunicação é vista como uma ferramenta importante que promove o elo entre a equipe de enfermagem, o paciente e a família, mediante o uso tanto da comunicação verbal quanto da não verbal. Não obstante se observa que alguns profissionais da equipe de enfermagem, apesar de reconhecerem a importância do emprego destas técnicas como recursos terapêuticos, demonstram não estar preparados para atuar em situações que envolvam a comunicação na terminalidade humana (ARAÚJO; SILVA, 2007; PINTO et al., 2011; SANTANA et al., 2009).

Assim, os membros da equipe de enfermagem evitam o contato verbal com os pacientes e familiares que vivenciam o processo de morrer, afastando-se por não saberem lidar com os sentimentos e emoções neles despertados pelo processo de morte, pois assistir à morte do outro é um momento difícil, que suscita sensação de tristeza, frustração, impotência e até mesmo de culpa por falhas na assistência prestada (ARAÚJO; SILVA, 2012a, 2012b; SANTANA et al., 2009). Isto se deve ao fato de que assistir ao morrer do outro remete o ser humano à reflexão sobre o que mais se nega: a finitude da vida humana. Deste modo, muitos profissionais utilizam a negação, a fuga e a aparente frieza como mecanismos de defesa no 
enfrentamento da situação.

Estes fatos se mostram de grande preocupação ao lembrar que a enfermagem é a profissão da área de saúde que interage mais direta e constantemente com o paciente e família durante o processo lento da terminalidade (ARAÚJO; SILVA, 2007; COSTA; CEOLIM, 2010; PINTO et al., 2011).

Assim, este estudo teve por objetivo refletir sobre a comunicação em cuidados paliativos e evidenciar estratégias utilizadas na comunicação efetiva entre a equipe de enfermagem, o paciente terminal e a família.

Para melhor compreensão do leitor, serão abordadas ao longo da reflexão algumas estratégias de comunicação como a verbal (veracidade, o escutar, o falar, o bom humor, as informações claras) e a comunicação não verbal (a postura, os gestos, as orientações do corpo, as expressões faciais, a empatia, o contato visual, o toque e a presença).

\section{Comunicando-se com o paciente terminal}

A origem do conceito sobre cuidados paliativos se deu na Inglaterra, com a médica inglesa Cicely Saunders, fundadora do St. Christopher Hospice em Londres, cujo objetivo era o de afirmar o cuidado daqueles que se aproximavam da morte (PESSINI, 2004). Cicely Saunders era formada em enfermagem, serviço social e, posteriormente ingressou na faculdade de medicina, e tornou-se a primeira doutora em cuidados paliativos. Essa pioneira era uma profissional da saúde preocupada com o descaso social em que viviam os pacientes em fase terminal e sua família. Essa preocupação trouxe consigo a criação e disseminação da filosofia dos cuidados paliativos (SALES et al., 2008).

Em sua fala, pode-se perceber a influencia positiva que a comunicação pode exercer como recurso terapêutico importante e efetivo frente ao processo doloroso da terminalidade: "Eu me importo pelo fato de você ser você, me importo até o último momento de sua vida e faremos tudo que está ao nosso alcance, não somente para ajudar você a morrer em paz, mas também para você viver até o dia da sua morte." (SAUNDERS apud ARAÚJO; SILVA, 2007, p. 669).

Nesse contexto, a veracidade é um dos princípios dos cuidados paliativos e uma das estratégias de comunicação a serem utilizadas; assim, deve haver honestidade na relação entre a equipe de enfermagem e o paciente ao expor a este o processo fisiológico pelo qual ele está passando ou ainda passará, ao ouvir o seu anseio, compreender e entender a comunicação não verbal e verbalizações simbólicas que ele expressar (ARAÚJO; SILVA, 2012a; COSTA; CEOLIM, 2010; SOUSA; CARPIGIANI, 2010).

Salienta-se que as tentativas de comunicação dos indivíduos em sua terminalidade podem passar despercebidas à equipe de enfermagem ou ser mal interpretadas, porque a comunicação pode ser obscura, inesperada ou expressa em linguagem simbólica e muitas vezes rotulada como confusão ou alucinação. Não obstante, há como decifrar as informações essenciais quando a equipe de enfermagem se atém às mensagens que recebe dos pacientes na iminência de morte, como também é possível realizar pequenas ações que ajudem amenizar a ansiedade e a aflição de quem está morrendo, proporcionando qualidade no cuidar da equipe de enfermagem e conquistando maior satisfação pessoal (ARAÚJO; SILVA, 2012a; CALLANAN; KELLEY, 1994; SANTANA et al., 2009).

Certas habilidades de comunicação - como $o$ escutar bem, não mentir nunca, evitar uma conspiração de silêncio, evitar falsa alegria, não descartar uma possível esperança, aliviar a dor, entre outras - tornam-se indispensáveis para a equipe de enfermagem proporcionar ao paciente uma assistência de qualidade, integral e humanizada (ARAÚJO; SILVA, 2012a, 2012b). Desta forma, o 
emprego adequado da comunicação constitui-se em um dos pilares dos cuidados paliativos e uma medida terapêutica comprovadamente eficaz. Por isso, a equipe de enfermagem representa nada menos que o suporte utilizado pelo paciente que o permite expressar e realizar alguns de seus anseios. Entretanto, um viés neste enfoque tem sido a falta de habilidade e conhecimento por parte da equipe de enfermagem no que se refere à comunicação com o paciente terminal e família, tornando-se esta a área que exige maior preparo (ARAÚJO; SILVA, 2012a, 2012b; JARDIM et al., 2010).

Além disto, na prática, muitas vezes a comunicação pode ser negligenciada, especialmente quando o paciente está impedido de expressar-se pela fala, por estar entubado ou sedado. Neste sentido, sabe-se que a audição é o último dos sentidos que o paciente perde neste processo de rebaixamento do nível de consciência. Não obstante, ocorrem alterações fisiológicas mensuráveis no paciente em coma quando este ouve a voz de um ente querido ou uma música que lhe era familiar (CALLANAN; KELLEY, 1994). Na incerteza de o paciente ainda estar ouvindo ou não, a equipe de enfermagem deveria partir sempre do pressuposto de que ele esteja ouvindo e sentindo as mensagens que lhe são verbalmente transmitidas.

É comum a equipe de enfermagem não conseguir estabelecer um canal de comunicação adequado, pois usualmente restringe o processo de comunicação apenas ao seu aspecto verbal, o falar. Assim, cria-se a falsa ideia de que não há troca de informações verbais, isto é, não há comunicação. Não obstante, sabe-se que apenas $7 \%$ da comunicação ocorrem através de palavras, enquanto a maior parte se dá por meio de expressões faciais e paralinguísticas. É denominada comunicação não verbal, toda informação obtida por meio de postura, gestos, orientações do corpo, expressões faciais e até mesmo pela relação de distância mantida entre os indivíduos (ARAÚJO; SILVA, 2007, 21012a; SANTANA et al., 2009). A comunicação não verbal utilizada pela equipe de enfermagem é fator determinante para o estabelecimento do vínculo de confiança do qual depende o cuidado ao doente sem possibilidade de expressar-se verbalmente.

Para pleitear tal processo, é importante utilizar sempre a empatia como instrumento da comunicação não verbal. Entende-se como empatia a capacidade de compreender e interpretar as emoções do outro, estabelecendo ressonância emocional entre as partes. Tem-se observado que os pacientes terminais esperam da equipe de enfermagem que lhes presta assistência essa empatia, a qual está diretamente relacionada com as habilidades que envolvem o "estar-com-o-outro" e, para tanto, é necessário ouvir e verbalizar sensivelmente, identificando a mensagem central e o sentimento, o contexto e a perspectiva (ARAÚJO; SILVA, 2012a, 2012b; PINTO et al., 2011;SALES et al., 2008).

$\mathrm{Na}$ tentativa de desenvolver e estabelecer um relacionamento empático com o paciente, a equipe de enfermagem expressa a essência de sua profissão reconhecendo-lhe a condição humana. Tal relacionamento gera ações que essa mesma equipe gostaria que fossem feitas para ela própria em situações semelhantes. Para tanto, esta equipe precisa ser honesta evitando, contudo, chocar o paciente e, para isso, é necessário saber o que o paciente sente e o que espera da assistência de enfermagem; não the dando falsas esperanças, mas também não lhe tirando a vontade de lutar pela vida (ARAÚJO; SILVA, 2003, 2012a; PINTO et al., 2011).

Neste contexto, "deve-se sempre procurar identificar a fase do processo de perda em que o paciente terminal se encontra: negação, raiva, barganha, depressão ou aceitação e, a partir de então, tentar adequar a técnica de comunicação à fase emocional do paciente" (KÜBLER-ROSS, 2000, p. 112).

Muitas vezes a equipe de enfermagem defrontase com intempéries emocionais do paciente em terminalidade. Assim, se o paciente expressa hostilidade e/ou raiva, deve-se tentar entender que 
tal sentimento não é dirigido ao enfermeiro, mas sim à sua doença, à sua condição terminal. Este é o momento de ouvir o paciente em silêncio, acolhendo seu desabafo. Certamente, o paciente sentirá alívio em expressar o turbilhão de sentimentos que o assola, ficando, assim, mais preparado para atravessar esta fase, seguindo em direção a um processo de morte mais consciente e tranquilo (JARDIM et al., 2010; KÜBLER-ROSS, 2000).

Neste sentido, os pacientes têm percebido o bom profissional de enfermagem como aquele que lhes olha nos olhos, ou seja, aquela pessoa que os observa com atenção e mostra dar importância àquilo que eles falam. Ao manter o contato visual por meio do olhar, o profissional da equipe de enfermagem passa a mensagem silenciosa de que se importa não apenas com o que o paciente está falando, mas também com o que ele está sentindo e expressando (ARAÚJO; SILVA, 2012a; JARDIM et al., 2010; PINTO et al., 2011).

Outro recurso efetivo da comunicação não verbal é o toque. Pode-se tocar a mão ou o braço, para demonstrar apoio, carinho e empatia ao paciente - que se sente só, que está com dor e que está morrendo - oferecendo-lhe os benefícios do gesto físico de solidariedade, já que os elementos sensoriais provocam alterações neurais, glandulares, musculares e mentais, as chamadas emoções. Além disso, tem-se a presença como outro recurso da comunicação não verbal, que se caracteriza pela distância interpessoal, sendo também uma forma de interagir com o paciente no processo de terminalidade (ARAÚJO; SILVA, 2003, 2012a, 2012b).

\section{Comunicando-se com a família}

A família representa a interface entre o doente e a equipe de enfermagem. Desta forma, o envolvimento da família no processo de comunicação na terminalidade da vida, torna-se imprescindível. Como advogada do doente, reivindica seus direitos, a humanização da assistência, subsidia informações relevantes, participa do processo de cuidado, auxilia nas estratégias de enfrentamento e promove conforto e segurança (COSTA; CEOLIM, 2010; JARDIM et al., 2010; LIMA; SILVA; SILVA, 2009).

Não obstante, alguns membros da equipe de enfermagem ainda acreditam que o cuidado aos familiares depende basicamente de habilidades e características individuais e que tal cuidado é de responsabilidade exclusiva de psicólogos e/ou assistentes sociais; mas apesar desses profissionais também serem de extrema importância no processo de cuidar, o cuidado aos familiares que enfrentam uma situação de terminalidade é de responsabilidade de todos, inclusive da equipe de enfermagem (OLIVEIRA; SILVA, 2010; SOARES, 2007; SOUSA; CARPIGIANI, 2010).

Assim, a comunicação vem a ser de igual modo a pedra angular do cui $\neg$ dado aos familiares, e para que esta seja efetiva, é fundamental a capacidade de ouvir. É preciso haver atenção para não desperdiçar as oportunidades durante os encontros com os familiares e nas discussões sobre cuidados na terminalidade (COSTA; CEOLIM, 2010; JARDIM et al., 2010; SOUSA; CARPIGIANI, 2010). Deste modo, dentre as áreas que requerem maior demanda de conhecimentos no cuidado do paciente sem prognóstico de cura, alguns integrantes da equipe de enfermagem consideram a comunicação como "ponto nevrálgico", ou seja, uma estratégia para o alívio da dor (ARAÚJO; SILVA, 2012b, p. 122).

Por outro lado, a comunicação causa grande ansiedadeà equipe de enfermagem, poiscadamembro da equipe se torna alvo de muitas expectativas de resolução de problemas que, por vezes, não podem ser alcançadas e de questionamentos que nem 
sempre podem ser respondidos (CALLANAN; KELLEY, 1994; LIMA; SILVA; SILVA, 2009).

Outro recurso em comunicação verbal vem sendo o emprego do bom humor. O bom humor entre familiares e equipe de enfermagem constitui uma terapêutica que permite aliviar a tensão inerente à gravidade da condição que os familiares enfrentam e, sobretudo, proteger a dignidade e os valores do paciente que vivencia a terminalidade. É comum que estas pessoas utilizem o humor para trazer à tona suas preocupações acerca da morte e do morrer (ARAÚJO; SILVA, 2007; PINTO et al., 2011).

O emprego do bom humor em locais onde se assistem pacientes em terminalidade está relacionado à própria filosofia dos cuidados paliativos, que destaca a significância da qualidade de vida e a importância dos relacionamentos, sendo um componente valioso da comunicação efetiva e terapêutica. Por outro lado, o humor nunca deve ferir a dignidade humana e precisa ser utilizado com muito cuidado e tato em situações de crise e de discussões sérias e quando há altos níveis de ansiedade.

Ao valorizarem o bom humor e a alegria, os familiares também destacam o otimismo como algo que desejam da equipe de enfermagem. Estimular os pensamentos positivos da família é um instrumento e uma habilidade de comunicação bastante útil, pois ser otimista significa manter certa normalidade na vida, apesar da doença (ARAÚJO; SILVA, 2007; PINTO et al., 2011).

Deve-se também empregar a comunicação verbal de forma clara e com a utilização de termos que sejam compreensíveis aos familiares, pois a utilização de expressões téc $\neg$ nicas ou do jargão médico pode impedir que o significado e a intenção de algumas assertivas não sejam assimilados adequadamente, podendo gerar nos familiares conflitos e sensações de abandono (COSTA; CEOLIM, 2010; SANTANA et al., 2009; SOARES, 2007).

Em suma, inserir os familiares no processo do cuidado, além de ser um ato de solicitude, é também hoje um conjunto de estratégias e in $\neg$ tervenções testadas e fundamentadas cientificamente que deveriam fazer parte do processo de formação de toda equipe de enfermagem que almeja e busca trabalhar com a abordagem em cuidados paliativos (LIMA; SILVA; SILVA, 2009; SANTANA et al.,

\section{Considerações finais}

Desvela-se neste estudo que, para a equipe de enfermagem, a assistência ao paciente terminal e seus familiares se torna de igual modo uma tarefa difícil, que suscita sensação de tristeza, frustração, impotência e até mesmo culpa por falhas na assistência prestada. Isto se deve ao fato de que assistir à morte do outro remete o cuidadorenfermeiro à reflexão sobre o que mais se nega: a finitude da vida humana. Deste modo, muitos profissionais da equipe de enfermagem se vestem de uma pseudo frieza, como mecanismo de defesa no enfrentamento da situação.

Não obstante vislumbra-se que, alguns membros da equipe de enfermagem que atualmente trabalham com pacientes terminais não aprenderam, em seu percurso de formação profissional, o adequado uso da comunicação no contexto dos cuidados paliativos. Em face disso, torna-se imprescindível que as instituições de ensino, seja em nível de graduação ou pós-graduação, ofereçam disciplinas que enfoquem o processo de comunicação de maneira efetiva com o paciente terminal e sua família, a fim de que seja preenchida esta possível lacuna existente na formação dos profissionais da enfermagem.

Da mesma forma, reitera-se a necessidade de que as instituições hospitalares ofereçam apoio psicológico à equipe de enfermagem que trabalha com pacientes em iminência de morte, pois somente aprendendo a lidar com seus próprios medos e limitações relacionadas ao processo de morte é que 
a equipe de enfermagem poderá prestar um cuidado holístico de acordo com as expectativas do paciente e sua família, englobando não apenas seus males físicos, mas também os aspectos interpessoais que permitem o cuidado humanizado.

\section{Referências}

ARAÚJO, M. M. T.; SILVA, M. J. P. Comunicando-se com o paciente terminal. Revista da Sociedade Brasileira de Cancerologia, São Paulo, v. 6, n. 23, p. 16-20, 2003.

A comunicação com o paciente em cuidados paliativos: valorizando a alegria e o otimismo. Revista da Escola de Enfermagem da USP, São Paulo, v. 41, n. 4, p. 668-74, 2007.

Estratégias de comunicação utilizadas por profissionais de saúde na atenção à pacientes sob cuidados paliativos. Revista da Escola de Enfermagem da USP, São Paulo, v. 46, n. 3, p. 62632, 2012a.

- O conhecimento de estratégias de comunicação no atendimento à dimensão emocional em cuidados paliativos. Texto Contexto Enfermagem, Florianópolis, v. 21, n. 1, p. 121-29, 2012 b.

CALLANAN, M.; KELLEY, P. Gestos finais: como compreender as mensagens, as necessidades e a condução especial das pessoas que estão morrendo. São Paulo: Nobel, 1994.

COSTA, T. F.; CEOLIM, M. F. A enfermagem nos cuidados paliativos à criança e adolescente com câncer: revisão integrativa da literatura. Revista Gaúcha de Enfermagem, Porto Alegre, v. 31, n. 4, p. 776-84, 2010.

JARDIM, D. M. B.; BERNARDES, R. M.; CAMPOS, A. C. V.; PIMENTA, G. S.; RESENDE, F. A. R.; BORGES, C. M.; SANTANA, J. C. B. O cuidar de pacientes terminais: experiência de acadêmicos de enfermagem durante estágio curricular. Revista Baiana de Saúde Pública, Salvador, v. 34, n. 4, p. 796-809, 2010.

KÜBLER-ROSS, E. Sobre a morte e o morrer. São Paulo: Martins Fontes, 2000.

LIMA, A. C.; SILVA, J. A. S.; SILVA, M. J. P. Profissionais de saúde, cuidados paliativos e família: revisão bibliográfica. Cogitare Enfermagem, Curitiba, v. 14, n. 2, p. 360-67, 2009.

OLIVEIRA, A. C.; SILVA, M. J. P. Autonomia em cuidados paliativos: conceitos e percepções de uma equipe de saúde. Acta Paulista de Enfermagem, São Paulo, v. 23, n. 2, p. 212-17, 2010.

PESSINI, L. A filosofia dos cuidados paliativos: uma resposta diante da obstinação terapêutica. In: PESSINI, L.; BERTACHINI, L. Humanização e cuidados paliativos. São Paulo: Loyola. 2004. p. 181-208.

PINTO, M. H.; CRUZ, M. F.; CESARINO, C. B.; PEREIRA, A. P. S.; RIBEIRO, R. C. H. M.; BECCARIA, L. M. O cuidado de enfermagem ao paciente oncológico fora de possibilidade de cura: percepção de um grupo de profissionais. Cogitare Enfermagem, Curitiba, v. 16, n. 4, p. 647-53, 2011.

RONCARATI, R.; CAMARGO, R. M. P.; ROSSETTO, E. G.; MATSUO, T. Cuidados Paliativos num Hospital Universitário de Assistência Terciária: uma necessidade? Semina: Ciências Biológicas e da Saúde, Londrina, v. 24, p. 37-48, 2003.

SALES, C.A.; SILVA, M. R. B.;BORGOGNONI, K.; RORATO, C.; OLIVEIRA, W. T. Cuidado paliativo: a arte de estar-com-o-outro de uma forma autêntica. Revista de Enfermagem da UERJ, Rio de Janeiro, v. 16, n. 2, p. 174-9, abr./jun. 2008.

SANTANA, J. C. B.; CAMPOS, A. C. V.; BARBOSA, B. D. G.; BALDESSARI, C. E. F.; PAULA, K. F.; REZENDE, M. A. E.; DUTRA, B. F. Cuidados paliativos aos pacientes terminais: percepção da equipe de enfermagem. Bioethikos, 
São Paulo, v. 3, n. 1, p. 77-86, 2009.

Silva, R. C. F.; HORTAle, V. A. Cuidados paliativos oncológicos: elementos para o debate de diretrizes nesta área. Cadernos de Saúde Pública, Rio de Janeiro, v. 22, n. 10, p. 2055-66, 2006.

SOARES, M. Cuidando da família de pacientes em situação de terminalidade internados na unidade de terapia intensiva. Revista Brasileira de Terapia Intensiva, São Paulo, v. 19, n. 4, p. 422-28, 2007.

SOUSA, K. C.; CARPIGIANI, B. Ditos, não ditos e entreditos: a comunicação em cuidados paliativos. Psicologia: Teoria e Prática, São Paulo, v. 12, n. 1, p. 97-108, 2010.

WORLD HEALTH ORGANIZATION. WHO definition of palliative care. Geneva: WHO, 2010. Disponível em: <http://www.who.int/cancer/ palliative/definition/en>. Acesso em: 19 ago. 2012. 